This is an author-produced PDF of a published article. The publisher-authenticated version is available online, copyright Taylor \& Frances. Citation information for that definitive version is:

Grant, C. (2014). Endangered musical heritage as a wicked problem. International Journal of Heritage Studies, 21(7), 629-641. DOI: 10.1080/13527258.2014.976245

Retrievable from http://dx.doi.org/10.1080/13527258.2014.976245.

\title{
Endangered musical heritage as a wicked problem
}

\author{
Catherine Grant ${ }^{1}$ \\ School of Creative Arts, University of Newcastle
}

The issue of the widespread decline and loss of musical heritage has recently found increasing prominence in ethnomusicological discourse, and many applied projects from grassroots to international levels strive to support genres perceived to be under threat. Much recent literature on the subject features rhetoric that draws on metaphors from ecology including, for example, the ideas of music 'ecosystems', 'endangerment', and 'sustainability'. Offering an alternative (though not contradictory) perspective, I here characterise the widespread loss of musical heritage as a 'wicked problem': one with complex interdependencies, uncertainties, and conflicting stakeholder perspectives, which defies resolution more than some of the ecological metaphors arguably imply. By drawing on theoretical notions of 'wickedness' from social policy planning and other areas, I aim to bring interdisciplinary insights to the discussion of strategies to mitigate the global threat to music as intangible cultural heritage. Offering three 'stories' about the problem of music genres 'at risk' and critiquing each of these stories against the theory of wicked problems, I explore the implications of this conceptualisation for heritage scholars, music researchers, policy-makers, and other cultural stakeholders, in terms of moving us closer to realising effective, resilient and innovative approaches to the problem at hand.

Keywords: Intangible Cultural Heritage; Music Endangerment; Musical Heritage; Music Sustainability; Wicked Problems

\section{Ways of Thinking about Music 'At Risk'}

Scholars have come (again) to focus some attention on the loss of musical heritage across the world. Particularly in the decade or so since UNESCO's Convention for the Safeguarding of Intangible Cultural Heritage (2003) came into force, ethnomusicologists and other researchers have explored with new interest various external pressures that contribute to situations of cultural and musical impoverishment and atrophy, including colonial power imbalances, social inequalities, and adverse political circumstances. The interest and concern

\footnotetext{
${ }^{1}$ Catherine Grant is Joy Ingall Postdoctoral Researcher at the School of Creative Arts, University of Newcastle (Australia). Her book Music Endangerment: How Language Maintenance Can Help was published by Oxford University Press in 2014. Correspondence to: Catherine.grant@newcastle.edu.au.
} 
in the issue is signalled by a range of local, national and international research projects and applied initiatives that aim to generate deeper understanding of, and support for, the predicament of music genres that may be under threat (cf., for example, Corn 2011; Coulter 2011; Letts 2003; ICTM-ANZ 2011; QCRC 2013; Saurman 2012; Seeger 2009; and Tan 2008).

The issue of musical heritage at risk has had a long and laden history within the discipline of ethnomusicology, and the somewhat disparaging labels of 'salvage' and 'white knight' ethnomusicology still cast shadows on present-day cultural preservation and renewal efforts, in a number of ways. Nowadays, former conceptualisations of 'dying' musical traditions are typically framed in less sentimental, more pragmatic terms, and discussions of the issue in the literature take care to acknowledge, rightly, that the vitality and very existence of music genres naturally ebb and flow over time. Music scholars also seem to concede, though, that current global circumstances - particularly the immense rate of social and technological change - places unprecedented pressure on many communities whose cultures lie 'at the weak end of power distribution' (Nettl 2005, 168), and that these pressures can lead to circumstances where the transmission and practice of certain music genres within these communities is significantly destabilised, against the will of the communities concerned. In this way, the future of this heritage is jeopardised (and a possible role presents itself to the applied ethnomusicologist to support those communities maintain these cultural expressions).

One way ethnomusicologists have recently conceptualised this problem (which I will call 'music endangerment') is in terms of sustainability, both from the perspective of creating viable futures for genres under pressure in the fast-changing contemporary world (e.g. Schippers 2010), and rather more expansively in reference too to the links between music and other sustainability concerns, such as economic and environmental ones (e.g. Titon 20082014, 2009). A survey of activity in (applied) ethnomusicological research in the last five years underscores the degree to which the rhetoric of sustainability has featured: 'music sustainability' is a focus of a 2009 edition of the journal World of Music (ed. Titon), a forthcoming edition of that same journal (ed. Schippers and Bendrups), and a 2013 special issue of Musicology Australia (ed. Bendrups and Barney); in 2010, sustainability was a focus area of the Applied Ethnomusicology Study Group meeting of the International Council for Traditional Music; the volume Applied Ethnomusicology: Historical and Contemporary Approaches devotes a section to research trajectories on that issue (ed. Harrison, Mackinlay and Pettan 2010); a forthcoming edition of the Grove Dictionary of Musical Instruments includes for the first time an entry on sustainability (Allen and Libin); and several chapters in Oxford's forthcoming Handbook of Applied Ethnomusicology explore the concept (e.g. those by Coulter, Schippers, and Titon).

A common approach to exploring music sustainability concerns has been to draw on a parallel with biological ecosystems. This is not unreasonable: both kinds of ecosystem (musical and biological), it can be argued, are dynamic and complex entities that can be defined by the network of interactions among their parts, and between those parts and their environment. Decades ago, Neuman suggested that 'a useful approach to the dynamics of Hindustani music is to view it ecologically' (1980, 203); more recently, Letts invoked the ecosystem analogy in relation to musical diversity (2006, 9-10); and Cottrell referred to risk of ethnomusicologists 'upsetting the delicate eco-systems that sustain fragile traditions' (and even of effecting a kind of 'mass-mediated musical Darwinism') (2011, 231). An example of this metaphor feeding into large-scale applied initiatives is the Australian-led project Sustainable Futures for Music Cultures: Towards an Ecology of Musical Diversity (QCRC 2013), which aims to support music sustainability by better understanding the distinct 
variables and processes within the 'ecosystems' in which these genres operate. The theoretical framework for the project (first presented in Schippers 2010, 180-181) categorises the ecosystems of music into five broad areas (systems of learning music, music and communities, contexts and constructs, media and the music industry, and policies and regulations).

Judging by its prevalence in the literature, the ecosystem metaphor has proven useful as a way to conceptualise the interaction of a music genre both with other genres and with the broader environment in which it operates. Pragmatically too, in relation to the issue of music endangerment, the ecosystem model is attractive on a number of counts: not least, it gives researchers of threatened musical heritage the defined (albeit highly complicated) task of working out the mechanisms of a music ecosystem well enough to be able to influence it in some desirable way (or to guide culture-bearers or communities to do so). Yet the metaphor also has limitations (Keogh 2013), and it is important for researchers and cultural stakeholders to recognise and take account of these, particularly if or when the metaphor is used to activate potential solutions to the problem.

In this paper I characterise the endangerment of musical heritage as a 'wicked problem'. In doing so, I aim to appraise and expand (rather than contradict) existing conceptualisations of music ecosystems, endangerment and sustainability, and to stimulate further consideration of the way ethnomusicologists and other cultural heritage stakeholders conceive of, and take action against, the problem of intangible heritage under threat.

\section{Wickedness}

The term wicked refers to problems that are complex, ill-defined, of indeterminate scope, and resist solution (Rittel and Webber 1973; Roberts 2000; Camillus 2008; Conklin 2006, 2009; Brown, Harris and Russell 2010; Kolko 2012). Wicked problems vary in kind and degree, but are typically social or cultural in nature - examples include poverty, Indigenous disadvantage, terrorism, the AIDS epidemic, nuclear energy and waste, and climate change. Often, stakeholders do not agree even on the very nature of the problem, let alone a solution. Not all difficult or substantial problems are wicked; some are non-complex (in the technical sense) and readily solvable at least in theory, if not in fact - landing a human on Mars, for example, or finding missing jet MH370. Part of the difficulty in solving wicked problems comes from their interdependency with other problems, the diversity of stakeholders and opinions involved, contradictory or incomplete information, and the typically large economic burden involved in solving them. The interconnectedness of any given wicked problem with others means that attempts at solution frequently expose or generate further problems, and unforeseen consequences are common (APSC 2007).

Closely related to the concept of wicked problems is that of 'messes' (Ackoff 1974), systems or sets of problems in which every problem interacts with others. As Horn points out, 'complexity - systems of systems - is among the factors that makes Social Messes so resistant to analysis and, more importantly, to resolution' $(2007,6)$. In Horn's articulation, the characteristics that define social messes overlap considerably with those that define wicked problems, including the lack of a single 'correct' view of the problem; divergent perspectives and illogical or 'alogical' thinking among stakeholders; interconnectedness with other problems; uncertain or missing data; considerable uncertainty and ambiguity; political and economic constraints; consequences that are difficult to imagine; considerable resistance to change; contradictory solutions; numerous possible approaches to intervention; and finally, those who are in a position to solve the problem are often out of contact with the problem and potential solutions. 
Though the term was coined in 1967 (by Churchman), it was Rittel and Webber who presented the first systematic formulation of wicked problems in a landmark social policy paper in 1973. Ackoff followed in 1974 with his theory of social messes. It was not long before scholars from disciplines other than social policy planning recognised the relevance to their own contexts of the concepts of wicked problems and social messes, and began claiming and adapting them for their own purposes. One example comes from the field of language endangerment, a problem Mufwene recognised as wicked over a decade ago (note he invokes the ecology metaphor in the same breath!):

Language endangerment is a more wicked problem than has been acknowledged in the literature. It sometimes boils down to the choice between saving speakers from their economic predicament and saving a language. Seldom can both goals be congruent unless the ecologies are made more advantageous to the relevant populations. (2002, 376-77)

To my knowledge, the concept has not been put to use in relation to endangered musical heritage.

\section{Music Endangerment as a Wicked Problem}

In an effort to generalise wicked problem theory, Conklin $(2006,2009)$ condensed Rittel and Webber's detailed set of characteristics to those he deemed most fundamental and relevant to contexts beyond social policy planning. It is Conklin's six-point framework that I draw on here to argue that the concept of wicked problems (and messes) may be a useful way to conceive of the problem of endangered musical heritage.

\section{The problem is not understood until a solution is formulated.}

Wicked problems may always be framed in more than one way, making them difficult even to articulate. The choice of how to describe and explain a wicked problem often determines how a solution is identified or formulated, and explanations will often reflect the (vested) interests, interpretations, intentions and worldviews of stakeholders. These stakeholders may be many and varied, since wicked problems interlock with other (sometimes also wicked) problems: socio-economic aspects interrelate with political and environmental ones, as well as with health, education, culture, and so on (Conklin 2009, 19). Writing about local responses to increasingly global approaches to heritage preservation in the Northern Territory (Australia), for example, Langfield (2010) provides insight into the multiple possible understandings of cultural heritage, and the challenges that arose in that context from competing stakeholder interests and expectations at the local and state levels.

In the case of the problem of music endangerment, stakeholders include musicians, other community members, researchers and academics, policy-makers, governments, nongovernment organisations (including UNESCO), training institutions, funding bodies, and enterprises like those in the tourism and music industry sectors (Grant 2014). Not surprisingly, these stakeholders perceive the problem - even the very existence of the problem - in very different ways. This has led to some considerably divergent ways to tackle the issue, from programs that focus on education and transmission (Afghan National Institute of Music, Cambodian Living Arts), to documentation and archiving initiatives (Smithsonian Institution, PARADISEC), to the celebration and promotion of the musicians and heritage genres in question (National Living Treasures schemes; UNESCO Intangible Cultural Heritage lists). Some of ways these varied stakeholders formulate the problem (and the solution) are examined in more depth later in this article.

\section{There is no stopping rule.}


In Conklin's words, "since there is no definitive "the problem", there is also no definitive "the solution"' $(2009,19)$, and therefore no conclusive way to decide when to stop efforts to solve wicked problems (no 'stopping rule'). Like the problem of climate change, or language endangerment, the problem of music endangerment will have no definitive end-point. Success will not be the point at which all musical heritage is kept vital in perpetuity (an absurd notion). Even if we may claim success in specific instances, at the wider level there will be no way of knowing when success has been reached, nor even any single way of even defining it. The extent of problem-solving in the case of music endangerment will therefore be dictated not by finding a solution, but rather by the availability of resources like time, funding, and energy.

\section{Solutions are not right or wrong.}

Because of their complexity, multi-causality, and interdependence with other problems, there is no single, linear, or easy way to solve wicked problems. Solutions therefore cannot be right or wrong; they can only be 'better/worse' or 'good enough/not good enough' (Conklin 2009,19). For the problem of music endangerment, whether at the level of individual genres or on the international scale, there are always multiple possible points of intervention. Determining the quality of a given solution (whether proposed or already carried out) is a subjective matter, and predicting the effects of an intervention is difficult (Grant 2012). Several researchers report on challenges in designing or implementing interventions in music endangerment, as well as unanticipated outcomes (e.g. Seeger 2009; Stobart 2010; Titon 2009; Wang 2003). I know of no instance where an intervention in a situation of music endangerment has been presented as the perfect solution, theoretically or practically.

\section{Each is essentially novel and unique.}

While experience can act as a guide, each wicked problem is essentially different. Language endangerment is perhaps one of the most similar problems to that of music endangerment (in addition to being interconnected with it); many of the same causal factors are present for each (Grant 2014). In relation to their sustainability, the similarities between language and music include certain aspects of their transmission processes, the potentially critical role of social and cultural constructs and attitudes, and the possible impact of economic and political circumstances. Nevertheless, there are striking dissimilarities too, like the greater potential for the mass media and industry to play a role in the vitality of music genres (Grant, 2014). The decades of experience in language maintenance and revitalisation can therefore only suggest pathways toward developing solutions for the global threat to music genres, not provide the solutions themselves. There is no precedent for solving the problem of music endangerment.

\section{Every solution is a 'one shot operation.'}

Every attempt at a solution counts significantly, because it changes the situation sufficiently to leave no opportunity to learn by trial and error. Conklin calls this the 'catch-22' of wicked problems: 'you can't learn about the problem without trying solutions, but every solution . . . has lasting consequences that may spawn new wicked problems' $(2009,19)$. Experience from the area of language maintenance - where both successful and unsuccessful efforts to increase the number of speakers of an endangered language have generated unexpected consequences, some good, some bad - suggests that is likely to be true for efforts to mitigate the problem of music endangerment too (Grant 2012). Adding another layer of complexity is the fact that the various factors causing a wicked problem typically evolve alongside efforts to solve them. In the case of musical heritage, these factors range from ongoing urban population drift through 
to the fast-changing technological advances in how music is created and distributed. This makes potential solutions into moving targets, complicating an already difficult situation.

\section{There is no given alternative solution.}

While many potential solutions may be proposed for any given wicked problem, 'another host are never even thought of', and for this reason 'it is a matter of creativity to devise potential solutions, and a matter of judgement to determine which should be pursued and implemented' (Conklin 2009, 19). Early in our discipline, the ethnographic documentation of 'dying' cultures was seen to be a solution to the problem of music endangerment, and this approach persisted through much of last century; documentation is still considered an integral part of what ethnomusicologists do. More recently, approaches have begun to expand, many of them positioned within an 'applied' or 'engaged' framework (Bithell 2011). Devising potential solutions to the global problem of music endangerment in its contemporary manifestations is still a relatively new concern of our discipline - no doubt there are indeed solutions we have not yet conceived of, and it remains to be seen whether our actions so far may be considered good judgement.

\section{Three 'Stories' about the Problem}

In this section, by way of both illustration and exploration, I take just one of the characteristics of wicked problems - namely, differing perspectives among stakeholders - and examine the implications for addressing the problem of endangered musical heritage. As described earlier, the various stakeholders in music endangerment (including culture-bearers and communities, fieldworkers and researchers, governments and policy-makers, music industry and media, and non-government cultural agents and agencies, among many others) have widely different frames of reference and even worldviews, meaning they are likely to frame, and to want to frame, the problem of music endangerment differently. Since it would take more space than this article permits to examine even briefly the ways in which all these stakeholders might perceive this problem, here I choose to focus on just one group: scholars, particularly those in the discipline of ethnomusicology. Like policy-makers and other 'experts' who can appear or intend to operate outside of the culture or cultural heritage in question, scholars themselves are in fact stakeholders in any heritage problem (Smith \& Waterton 2009). Indeed, in Schippers' terminology, when researchers undertake applied work in the area of music sustainability, they are not 'interfering' with the 'ecosystems' of music: they become a part of them (forthcoming).

Even among this single group of stakeholders - ethnomusicologists and other scholars - there exists a range of perspectives on the problem at hand. This no doubt results at least in part from the diverse relationships ethnomusicologists have with musicians and communities, and correspondingly diverse values and attitudes about how scholarly and applied activities can and should find resonance in the local and global contexts in which they operate. The various perspectives of scholars on issues of cultural loss may be distilled - somewhat grossly, but still hopefully usefully - into three 'stories' (a notion adopted from APSC 2007). Each story emphasises different aspects of the problem; each largely defines itself in contradistinction to other stories, and proposes different solutions.

1. Endangerment and loss. This is the story that is characterised by rhetoric of endangerment, loss, threat, and the 'dying' or 'death' of music (and cultures more generally). This rhetoric remains somewhat provocative among ethnomusicologists. In their disciplinary past, charges of romanticism, neo-colonialism, and paternalism have 
arisen against this story (Myers 1992; Wong in QCRC 2008); the resulting proposed solutions have been sometimes rather pejoratively dubbed 'salvage' or 'white knight' efforts. In this story, one of the key underlying problems is often seen to be the inequalities between colonial powers and the colonised. This leads to the notion of agents that are morally responsible for the problem, such as governments, or more intangibly, the forces of colonialism and globalisation.

This story typically leads to policy solutions that aim to 'protect and promote' or to 'safeguard' musical heritage from the threats arising from these agents. Examples of such solutions are found in a number of top-down methodologies for the preservation of intangible cultural heritage, such as the Living National Treasures (sometimes called Living Human Treasures or Intangible National Treasures) systems operating in a number of countries, and UNESCO's List of Masterpieces of Oral and Intangible Cultural Heritage in Urgent Need of Safeguarding (Ahmad, 2006; Schmitt, 2008). While these kinds of cultural preservation schemes represent some of the most high-profile methodologies for supporting music practices, within the discipline of ethnomusicology they continue to be contentious for various reasons - not least their equivocal impact on the communities and heritage in question (Seeger 2009; Smith and Akagawa 2009; Titon 2009).

With regard to the theory of wicked problems, to some extent this story (like all stories) tames the problem of music endangerment - first, by trying to 'lock down the problem definition' (Conklin 2009) (that is, that powerful agents are responsible for the problem); and second, by identifying a discrete and somewhat detached set of approaches to solving it (namely, protect and promote what remains through a series of carefully constructed local and global strategies).

2. Sustainability and ecology. This story sees the main problem to be the disappearance of, or disruption to, the set of conditions that support(ed) a given music genre. Rhetoric of sustainability, environment, ecology, and ecosystems is commonplace. The story typically emphasises musical traditions as living cultural and creative practices (rather than as heritage to be protected and preserved, as in the previous story); in this way, it resonates with Harvey's characterisation of heritage 'as a process, or a verb, related to human action and agency' $(2001,320)$. This story may or may not point to specific agents or factors that may be held responsible for the problem (like colonial powers or the spread of globalisation); regardless, solutions do not generally aim to protect music from these. Instead, solutions tend to aim to (re)create a viable environment, a workable context, for music genres. In contrast to the first story, this one takes a systemic view of the problem, a view that 'the issue is not whose fault the mess is' but rather 'the issue is our collective failure to recognize the recurring and inevitable dynamics of the mess' (Conklin 2009, 29).

An example of this story is the Sustainable Futures for Music Cultures project mentioned earlier (QCRC, 2013), which employs a five-domain classification of the 'ecosystems' in which music genres operate. The project offers an online tool to help identify areas of strength and weakness (or opportunity and threat) for any given music genre within its ecosystem; the general idea is that by addressing the weaknesses and (where possible) the threats, the health of the music genre itself may improve. This kind of story may be attractive to ethnomusicologists partly for its potential for local self-determination, since ecosystems may be defined as minutely or 
as broadly as is practicable in any given situation, and solutions may therefore be developed, trialled, and monitored at the grassroots as well as higher levels.

This story has parallels with one found in the biological sciences, where the study of 'ecosystems management' attempts to promote the long-term sustainability of biological ecosystems. Scientists have variously attempted (without consensus) to compartmentalise those ecosystems into ecologically homogenous elements, believing this to be an essential step towards effective ecosystems management (Christensen et al 1996). Comparably, classifying the elements of music ecosystems as a step towards effecting long-term sustainability (as in the Sustainable Futures project) relies on researchers' 'best understanding of the ecological interactions and processes necessary to sustain ecosystem structure and function' (Christensen et al 1996, 668-669). As in biological ecosystems management, this story suggests that solutions to the problem of music endangerment will be most possible when we achieve a thorough understanding of the ecosystem(s) in which genres operate, including the interaction of the various elements involved, and the contexts and dynamics of the system itself. From the perspective of the theory of wicked problems, then, this story, like the first, tames the problem by locking down both the problem definition and the solution (if only in theoretical terms).

3. Much ado about nothing. I retain this descriptor of this story from APSC (2007), where it is used to designate the view that the concern about climate change is 'scaremongering' by 'idealists':

Some with this view are sceptical about the diagnosis of climate change itself, while others are convinced that, even if correct, the consequences will be neither catastrophic nor uniformly negative. ('Climate Change - A Wicked Problem' section)

Without necessarily wanting to equate the gravity of the problem of music endangerment with that of climate change - the latter threatening the very future of humanity and most other life forms on the planet - this 'scaremongering' sentiment is found, at least to some degree, towards both problems. In the course of discussing with colleagues my own involvement with the issue of endangered musical heritage over the past few years, I have not infrequently encountered scepticism about whether the problem, if it exists at all, is cause for concern. Reservations are variously expressed, and run along a spectrum from indifference to resignation: the loss of some music genres is balanced by the rise of many others, especially given the new possibilities opened up by cross-cultural influences and collaborations; it'd be more accurate to talk about the 'change to' rather than 'loss of' musical practices within a community; the atrophy (and genesis) of music and other cultural practices is a natural and expected response to the changing environment; the loss of musical heritage is an inevitable, if somewhat regrettable, consequence of local and global change; and so on. This story of 'much ado about nothing' is the one least documented within the music-related literature, perhaps simply because those who espouse it are least likely to engage with the issue - or, for that matter, with developing possible solutions. This story does not so much tame the problem, then, as overlook it. Like the other two stories, it has an important contribution to make to our understanding of the issue at hand, but does not represent the complete picture.

These three 'stories' underscore the difficulties we face in attempting to address the problem of endangered musical heritage. The range of perspectives leads scholars down different 
pathways to different problems, and these lead to approaching possible solutions differently too. Sometimes the process unfolds conversely: different solutions lead to different problems, as perhaps in the case of UNESCO, a well-established international body with a pre-defined remit around global cultural heritage preservation and protection. What might we take from this tricky situation, in which the very problem eludes us?

\section{Implications}

First, it should be noted that the wickedness of the problem of music endangerment is not an excuse for lack of action, or delayed action. Action is urgent. As Conklin warns, 'pure study amounts to procrastination, because little can be learned about a wicked problem by objective data gathering and analysis' $(2001,10)$. As time passes, and as knowledge about specific musical practices is lost, the harder will be the task of sustaining these and other 'small' music genres, with loss of diversity of musical heritage potentially following an exponential trajectory. Marett (2010) convincingly argues that the widespread disappearance of songs and other performative cultural heritage has potentially devastating consequences for humanity. For this reason, a strong case may be made for coordinated strategies being implemented simultaneously or even in advance of further research (Grant 2014).

Second, even if solutions are hard to identify, let alone realise, careful policy planning and action can mitigate the adverse effects of wicked problems (Brown et al 2010). At the same time, it will be prudent to keep in mind that the process will not be fast or easy, and that wicked problems are by their very nature never definitively solved, not least because the problems themselves cannot be defined clearly. It is for this reason that drawing convincing workable solutions to the problem of endangerment, both in specific contexts and generally, is neither possible nor desirable. Nevertheless, this is no cause for despondency. We may take a leaf out of the book of sociolinguists, who continue to tackle the wicked problem of language endangerment with fierce passion and commitment despite the enormity of the task - with 'pessimism of the intellect and optimism of the will', in Antonio Gramsci's well-known words. Scholars can play a range of important roles in ameliorating the trajectory of cultural endangerment, for example by influencing policy; by advocating within, with, and for communities; and by helping develop and implement practical strategies to support endangered genres. There is work to be done, and we should do it.

Third, we might conclude that rational-scientific approaches to solving the problem of music endangerment - using case-by-case or overarching analysis to develop a linear course of action towards a clearly defined goal - are unlikely to work. This is true also for other forms of intangible cultural heritage. The stories presented earlier in this paper suggest that when faced with a problem both ill defined and complex, humans quite naturally tend to 'tame' it, to 'simplify it in various ways to make it more manageable and solvable' (Conklin, 2009). For cultural heritage scholars, that is arguably true whichever of the three stories we most align with in our own research approaches and frameworks. Yet Conklin warns that despite the appeal, 'attempting to tame a wicked problem always fails in the long run. The problem will simply reassert itself, perhaps in a different guise, as if nothing had been done; or worse, the tame solution will exacerbate the problem' $(2001,10)$. Rather than simplified or linear solutions, wicked problems demand an exploratory and creative approach (Conklin et al 2007).

What might such an approach look like, for the problem of music endangerment? There are a number of possibilities. Roberts (2000) identifies several strategies to cope with wicked problems. The 'authoritative' strategy - vesting responsibility for such problems in the hands of a few - reduces competing stakeholder perspectives and therefore the complexity 
of the problem. On the downside, it also divests those responsible for the solution from the ability to access the variety of perspectives that may be necessary to mitigate the problem. 'Competitive' strategies that require diverse stakeholders to create their own solutions, which are then pitted against each other, allow a variety of solutions to be weighed up, and the best one selected; but this approach discourages knowledge-sharing and collaboration between parties, and may lead to cultural heritage stakeholders prioritising their own needs.

As an alternative to these restrictive or confrontational processes, a third possibility is to employ strategies that engage all stakeholders, who may then work together to formulate the best possible solution for all those involved ('collaborative' strategy). This has the benefit of allowing the active participation of all those who may be affected. Crucially, this includes culture-bearers and communities themselves, who should ultimately have the right to determine the future of their own cultural heritage. The major disadvantage of this collaborative approach is that reaching a shared understanding and commitment to acting on the wicked problem of cultural loss is a difficult and time-consuming process. Various social policy research over the last decade or two has proposed several concrete ways to facilitate collaborative strategies to address wicked problems, including technology-assisted techniques that allow the intelligence of a group of problem-solvers to emerge naturally (Brown et al 2010; Horn 2001; Horn and Weber 2007).

The complex 'systems of systems' quality of wicked problems like music endangerment (and the endangerment of other forms of intangible cultural heritage) means that solutions do not lie within one field or discipline. Instead, they demand interdisciplinary knowledge and collaboration. For this reason, dealing with wicked problems in general is 'fundamentally a social process' (APSC 2007). In other disciplines, failing to recognise this fact has been one reason for the failure of strategies to cope with wicked problems:

In addition to being overwhelmed by complexity, working groups fail to resolve these issues because they often fall victim to the bureaucratic silo effect: decision-makers fail to look beyond the boundaries of their own interest group, organization, department, etc., or they believe that it's the responsibility of someone in another silo to fix the Wicked Problem at hand. (Horn and Weber 2007, 3)

If we scholars are to progress with our efforts to support a viable and vibrant future for musical and other intangible cultural heritage across the world, we might do well to engage stakeholders across relevant disciplines - politics, technology, economics, environmental sciences, tourism, industry, and others - in rigorous discourse and enquiry (in addition to communities themselves). Dealing with wicked problems is 'not at all a matter of coming up with the best answer; rather, it's about engaging stakeholders in a robust and healthy process of making sense of the problem's dimensions' (Conklin 2009, 18). If we do this, we will be building nuanced individual, collective, and interdisciplinary understanding that will position us best to develop strategies to tackle the intractable problem at hand.

\section{References}

Ackoff, Russell. 1974. Redesigning the Future. New York/London: Wiley.

Ahmad, Yahaya. 2006. 'The Scope and Definitions of Heritage: From Tangible to Intangible.' International Journal of Heritage Studies 12(3):292-300.

Allen, Aaron and Laurence Libin. Forthcoming. 'Sustainability.' Grove Dictionary of Musical Instruments, $2^{\text {nd }}$ ed. New York: Oxford University Press.

Australian Public Services Commission (APSC). 2007. Tackling Wicked Problems: A Public

Policy Perspective. http://www.apsc.gov.au/publications-andmedia/archive/publications-archive/tackling-wicked-problems. (Accessed 3 April 
2014).

Bendrups, Dan and Katelyn Barney (Eds). 2013. Musicology Australia. Special Issue:

Sustainability and Ethnomusicology in the Australian context 35(2).

Bithell, Caroline. 2011. 'Desperately seeking impact.' Ethnomusicology Forum 20(2):233244.

Brown, Valerie A., John A. Harris and Jacqueline Y. Russell (Eds). 2010. Tackling Wicked Problems: Through the Transdisciplinary Imagination. London, Washington DV: Earthscan.

Camillus, J.C. 2008. 'Strategy as a Wicked Problem'. Harvard Business Review, 86: 98-101.

Christensen, Norman L.; Ann M. Bartuska; James H. Brown; Stephen Carpenter; Carla D'Antonio; Robert Francis; Jerry F. Franklin; James A. MacMahon; Reed F. Noss;

David J. Parsons; Charles H. Peterson; Monica G. Turner; and Robert G. Woodmansee. 1996. 'The Report of the Ecological Society of America Committee on the Scientific basis for Ecosystem Management.' Ecological Applications 6(3): 665-691. doi:10.2307/2269460. (Accessed 13 April 2014).

Churchman, C. West. 1967. 'Wicked Problems'. Management Science 14(4).

Conklin, Jeffrey. 2001. 'Wicked Problems and Social Complexity.' CogNexus Institute. [Online]. http://cognexus.org/wpf/wickedproblems.pdf. (Accessed 14 April 2014).

Conklin, Jeffrey. 2006. Dialogue Mapping: Building Shared Understanding of Wicked Problems. Chichester, England: Wiley.

Conklin, Jeffrey. 2009. 'Building Shared Understanding of Wicked Problems'. Rotman Magazine (Winter 2009). http://www.cognexus.org/Rotmaninterview_SharedUnderstanding.pdf. (Accessed 10 February 2014).

Conklin, Jeffrey, Min Basadur and G.K. VanPatter. 2007. 'Rethinking Wicked Problems: Unpacking Paradigms, Bridging Universes' (Part 1). NextDesign Leadership Institute Journal. [online] http://issuu.com/nextd/docs/conv28. (Accessed 10 February 2014).

Conklin, Jeffrey, Min Basadur and G.K. VanPatter.. 2007. 'Rethinking Wicked Problems: Unpacking Paradigms, Bridging Universes' (Part 2). NextDesign Leadership Institute Journal. [online] http://issuu.com/nextd/docs/conv30. (Accessed 10 February 2014).

Corn, A. 2011. 'National Recording Project for Indigenous Music in Australia.' http://www.aboriginalartists.com.au/NRP.htm. (Accessed 30 April 2014).

Coulter, N. R. 2011. 'Assessing Music Shift: Adapting EGIDS for a Papua New Guinea Community'. Language Documentation and Description 10:61-81.

Grant, Catherine. 2012. 'Rethinking Safeguarding: Objections and Responses to Protecting and Promoting Endangered Musical Heritage'. Ethnomusicology Forum 21(1): 39-59.

Grant, Catherine. 2014. Music Endangerment: How Language Maintenance can Help. New York: Oxford University Press.

Harvey, David C. 2001. 'Heritage Pasts and Heritage Presents: Temporality, Meaning and the Scope of Heritage Studies.' International Journal of Heritage Studies 7(4):319-338.

Horn, Robert E. 2001. Knowledge Mapping for Complex Social Messes. Presentation to the 'Foundations in the Knowledge Economy' conference, July 16, 2001. http://www.stanford.edu/ rhorn/SpchPackard.html. (Accessed 7 April 2014).

Horn, Robert E. and Robert P. Weber. 2007. 'New Tools for Resolving Wicked Problems: Mess Mapping and Resolution Mapping processes.' http://www.strategykinetics.com/New_Tools_For_Resolving_Wicked_Problems.pdf. (Accessed 10 February 2014). 
ICTM-ANZ (International Council for Traditional Music Australia-New Zealand Regional Committee). 2011. 'Statement on Indigenous Australian Music and Dance.' http://www.ictmusic.org/sites/default/files/documents/IAMD_statement.pdf. (Accessed 30 April 2014).

Keogh, Brent. 2013. 'On the Limitations of Music Ecology'. Journal of Music Research

Online 4. http://www.jmro.org.au/index.php/mca2/article/view/83. (Accessed 3 August 2014).

Kolko, Jon. 2012. Wicked Problems: Problems Worth Solving. https://www.wickedproblems.com (Accessed 10 February 2014).

Langfield, Michele. 2008. 'Global Heritage: Perspectives from the Northern Territory, Australia.' International Journal of Heritage Studies 16(3):187-206.

Lazarus, Richard James. 2009. 'Super Wicked Problems and Climate Change: Restraining the Present to Liberate the Future'. Cornell Law Review 94(5): 1153-1233. http://papers.ssrn.com/sol3/papers.cfm?abstract_id=1302623. (Accessed 10 February 2014).

Letts, R. 2003. The Effects of Globalisation on Music in Five Contrasting Countries: Australia, Germany, Nigeria, the Philippines and Uruguay. http://www.mca.org.au/research/research-reports/research-reports/638-the-effects-ofglobalisation-on-music-in-five-contrasting-countries-australia-germany-nigeria-thephilippines-and-uruguay. (Accessed 30 April 2014).

Levin, Kelly, Benjamin Cashore, Steven Bernstein, and Graeme Auld. 23 May 2012.

'Overcoming the Tragedy of Super Wicked Problems: Constraining our Future Selves to Ameliorate Global Climate Change'. Policy Sciences 45(2): 123-152.

http://link.springer.com/article/10.1007\%2Fs11077-012-9151-0. (Accessed 12 February 2014).

Marett, Alan. 2010. 'Vanishing Songs: How Musical Extinctions Threaten the Planet.

Laurence Picken Memorial Lecture 2009. Ethnomusicology Forum 19(2): 249-262.

Mufwene, Salikoko S. 2002. 'Colonisation, Globalisation, and the Plight of 'Weak' Languages: A Rejoinder to Nettle \& Romaine's Vanishing Voices'. Journal of Linguistics 38: 375-395.

Myers, Helen. 1992. 'Fieldwork'. In Helen Myers (Ed.), Ethnomusicology: An Introduction, 1: 21-49. London: Macmillan.

QCRC (Queensland Conservatorium Research Centre). 2008. 'Twelve Voices on Sustainable Futures' [Video recording]. Brisbane: Queensland Conservatorium Research Centre.

QCRC. 2013. 'Sustainable Futures: Towards an Ecology of Musical Diversity'. http://musecology.griffith.edu.au/. (Accessed 1 November 2013).

Roberts, Nancy. 2000. 'Coping with Wicked Problems'. Working Paper. Monterey, California: Department of Strategic Management, Naval Postgraduate School.

Rittel, Horst W. J. and Melvin M. Webber. 1973. 'Dilemmas in a General Theory of Planning'. Policy Science 155: 160-169.

Saurman, Todd. 2012. 'Singing for Survival in the Highlands of Cambodia: Tampuan Revitalization of Music as Cultural Reflexivity'. In Ursula Hemetek, (Ed.), Music and Minorities in Ethnomusicology: Challenges and Discourses from Three Continents, 95-103. Vienna: Institut für Volksmusikforschung und Ethnomusikologie. http://www.mdw.ac.at/ive/?PageId=3650. (Accessed 30 April 2014).

Schippers, Huib. 2010. Facing the Music: Shaping Music Education from a Global Perspective. New York: Oxford University Press. 
Schippers, Huib. Forthcoming. 'Applied Ethnomusicology and Cultural Sustainability: Understanding 'Ecosystems' of Music as a Tool for Sustainability'. In Svanibor Pettan and Jeff Todd Titon (Eds.), Handbook of Applied Ethnomusicology. New York: Oxford University Press.

Schmitt, Thomas. 2008. 'The UNESCO Concept of Safeguarding Intangible Cultural Heritage.' International Journal of Heritage Studies 14(2):95-111.

Seeger, Anthony. 2009. 'Lessons Learned from the ICTM (NGO) Evaluation of Nominations for the UNESCO Masterpieces of the Oral and Intangible Heritage of Humanity, 2001-5'. In Laurajane Smith and Natsuko Akagawa (Eds.), Intangible heritage, 112128. London: Routledge.

Smith, Laurajane, and Natsuko Akagawa (Eds.). 2009. Intangible Heritage. London: Routledge.

Smith, Laurajane, and Emma Waterton. 2009. Heritage, Communities and Archaeology. London: Gerald Duckworth and Co.

Stobart, Henry. 2010. 'Rampant Reproduction and Digital Democracy: Shifting Landscapes of Music Production and "Piracy" in Bolivia'. Ethnomusicology Forum 19(1): 27-56.

Tan, S. B. 2008. 'Activism in Southeast Asian Ethnomusicology: Empowering Youths to Revitalize Traditions and Bridge Cultural Barriers'. Musicological Annual 44(1): 6983.

Titon, Jeff Todd. 2008-2014. 'Sustainable Music' [blog]. http://sustainablemusic.blogspot.com.au. (Accessed 30 April 2014).

Titon, Jeff Todd. 2009. 'Music and Sustainability: An Ecological Viewpoint'. World of Music, 51(1): 119-137.

Titon, Jeff Todd. Forthcoming. 'Resilience.' In Svanibor Pettan and Jeff Todd Titon (Eds.), Handbook of Applied Ethnomusicology. New York: Oxford University Press.

Wang, Ying-Fen. 2003. 'Amateur Music Clubs and State Intervention: The Case of Nanguan Music in Postwar Taiwan'. Journal of Chinese Ritual, Theatre and Folklore 141: 95167. 